\title{
Community perspective on family medicine and family physician in Saudi Arabia 2020
}

\author{
Manal Abdulaziz Murad ${ }^{1 *}$, Rawan Maatouk Kheimi², Mohammed Majdi Toras ${ }^{3}$, Rahaf Hussain Alem4, \\ Atheer Meshal Aljuaid ${ }^{5}$, Jafar Naji Alobaidan ${ }^{6}$, Hebah Yousef Binishaq ${ }^{7}$, Abdulrahman Ahmed Asiri ${ }^{8}$ and \\ Manar Khalid Sagga ${ }^{4}$
}

\begin{abstract}
Background: Despite the importance and advantages of family medicine, it has poorly developed in Arab communities when compared to other medical specialties. Therefore, in this study, we aim to investigate the perception of the Saudi population about family medicine and physicians.

Materials and methods: A cross-sectional study was carried out using a self-administered structured online survey tool through the Google Forms platform. The online questionnaire was distributed to all Saudi Arabia's residents aged more than 15 years. A predesigned questionnaire was used and included items collecting data about participants' sociodemographic characteristics, awareness/knowledge, and experience/attitudes.

Results: A total of 6974 valid participants were included in the current study, where the age group 25-35years (37.1\%) and $51.7 \%$ of them were females. Out of the included participants, $81.3 \%(n=5671)$ did not report any chronic illnesses, while the other $18.7 \%(n=1303) \mathrm{did}$. The mean awareness and knowledge score for all participants was $9.57 \pm 3.39$ (out of 20 possible points), while the mean experience and attitude score for all participants was $10.15 \pm 2.58$ (out of 16 possible points). Patients' perceptions, whether awareness and knowledge or experience and attitude scores, were significantly correlated $(P$-value $<0.001)$ to chronic illness status, being a healthcare worker, job, marital status, and gender factors. Moreover, experience and attitude score was additionally correlated to residence region $(P$-value $=0.034)$ and participants' nationality $(P$-value $<0.001)$.

Conclusion: General population in Saudi Arabia were aware about the importance of family physicians and they trust them. The identified predictors should be considered when trying to increase public awareness and enhance the experience with family physicians.
\end{abstract}

Keywords: Family medicine, Saudi, Perception, Awareness, Attitude

\section{Introduction}

In 1969, family medicine specialty was first inaugurated in the United States by the American Board of Specialties on recommendations of Citizens' Commission on Medical Education of the American Medical Association, also

\footnotetext{
*Correspondence: mmurad@kau.edu.sa

${ }^{1}$ Department of Family Medicine, Faculty of Medicine, King Abdulaziz

University, P.O.Box 80205, Jeddah 21589, Saudi Arabia

Full list of author information is available at the end of the article
}

known as the Millis Commission and Ad Hoc Committee on Education for Family Practice of the Council of Medical Report Education of the American Medical Association, also called the Willard Committee (1966) [1]. The role of family medicine is to take care of various communities regardless of their background or ethnicity. It is meant to provide various health care services that is tailored at enhancing the prognosis of many disorders and improving the quality of life for patients by improving the community's health. To achieve this, it must depend 
on firs-contact care, continuous care, coordinated care, and comprehensive care which family medicine is built to provide [1, 2]. Although many benefits have been recorded as a result of family medicine practices, it is rarely researched as it growing to become a vital specialty in the medical field.

Patients' opinions about primary care services have changed in the past two decades in Saudi Arabia ever since the Ministry of Health $(\mathrm{MoH})$ of Saudi Arabia made it compulsary for admission to hospitals to be through primary care center transfers, except for emergency treatments [3]. This is mostly due to the huge changes in society and patterns of life in many communities which eventually impacts the overall quality of health services $[4,5]$. Demands to improve the quality of provided care, the economic burden, and the increased incidence of many morbidities mainly contribute to the organization and enhancement of the provided health care in this field [5]. A successful family medicine practice relies mainly on the relationship between a doctor and his patient. This implies the importance of cooperation between patients and their doctors to provide the required information relevant to their health status [6]. In Saudi Arabia, family medicine practice model is an individual doctor-patient interaction which takes place in primary care centers, which is a governmental public care sector, with a vision to transfer the system into a national health insurance system [7]. It has been reported that patients' satisfaction with the provided health service is mainly dependant on attending physicians' practices and attitudes [8]. Moreover, although many advances have been introduced in the healthcare and nursing fields, the association between patients and doctors will always remain the best tool for achieving better prognostic outcomes [9]. A successful doctor-patient relationship is mainly dependant on the satisfaction of the offered healthcare advice and on following these instructions that are provided by the patient's doctor [10]. Better compliance has been reportedly associated with the enhanced quality of family medicine and the detailed information for patients that consequently lead to more satisfaction and more willingness to cooperate $[4,11]$. This indicates the importance of improving family medicine and the relationship between patients and doctors.

Despite the importance and advantages of family medicine, it has been poorly developed in Arab communities when compared to other medical specialties [12]. The specialty of family medicine was first introduced in Saudi Arabia in the early 1980s which was the threshold for many subsequent events that led to big advances in the field [13]. The current family medicine program in Saudi Arabia is run by the Saudi
Commission for Health Specialties (SCFHS). Previously the program was divided into a higher diploma of 2 years, and residency of 4 years duration. In 2020, the model of the program was changed to have only a residnecy program of 3 years duration. Previously, only institutes offered residency seats. At the moment, the SCFHS have included many primary care centers across the country to increase the capacity of family medicine residents due to the increasing demand on them and the expansion of more primary care centers across the country. According to the MoH of Saudi Arabia, the total number of primary care centers in 2012 was 2259 [14]. An increase in that number is expected to have hit the 3000 centers by 2021 . Nonetheless, there is yet to be any national survey to find the actual number of practicing family physicians in Saudi Arabia and their distribution. Meanwhile, conferences, community activities and research among family medicine physicians is being supervised by the Saudi Society of Family and Community Medicine [15]. However, previously published reports concluded that family medicine services need to be improved in several aspects [16-19]. Additionally, it has been noticed that many patients are not aware of the roles and services provided by the family physician despite the adequate presence of these physicians in healthcare facilities and primary care centers. Not many studies have invistigated the public's knowledge, experience and satisfaction about family medicine and physicians $[20,21]$. Therefore, in this study, we aim to investigate the awareness, attitudes, and satisfaction among Saudi population about family medicine physicians and find the common misconseptions about family medicine in the community.

\section{Methods}

\section{Study design}

This is a cross-sectional study that was carried out using a self-administered structured online survey tool through Google Forms platform from 1st of January 2019 until 30th of December of 2019. The online questionnaire was distributed to all Saudi Arabia's residents through social media and community online groups with snowballing sampling technique where participants were asked to send the sample for other acquintances from friends or family groups [22]. The inclusion criteria were all residents who agreed to participate in the study and aged more than 15 years. There were no restrictions on gender, nationality, occupation, residence, or socioeconomic level of the participants. The exclusion criteria were all residents less than 15 years, and incomplete data submissions. All methods were 
performed in accordance with the guidance provided in the Declaration of Helsinki.

\section{Sampling technique and data collection}

Snowball sampling was used to recruit the study participants. An online link to the web-based questionnaire was developed by using Google Forms. On the first section, a Plain Language Information Statement (PLIS) and Consent Form were presented. Only the participants who provided consent and agreed to participate in the study could move to the next section containing the screening questionnaire to confirm the age of $>15$ years. The choice of making the cutoff age to be 15 was based on studies that was done stating that adolescents of 14-15 years of age are as competent as adults [23, 24]. Furthermore, in the United Kingdom, those who are 16 years and older can make their own medical decision and provide consent with cases of being as young as 12 years old. Similarly, in Saudi Arabia, the age of which a person can provide medical consent is 16 years old. It is worth mentioning, that in Saudi Arabia, Family Physicians either work in primary care governmental centers or practice in large hospitals. There are yet to be any private GP practice in the country. Upon confirmation, the participants were able to access and fill in the self-administered questionnaire with their personal data being anonymous. An invitation with the online survey link was shared on different social media platforms and online community networks. To avoid potential coercion, healthcare providers were not involved in the recruitment of study participants or collecting data from patients. A total of 6974 valid participants were included in the current study.

\section{Study instrument}

A predesigned questionnaire was used and included data about participants' sociodemographic characteristics (age, gender, region, occupation, marital status, number of children, educational level, nationality, housing, and monthly income). Regarding face validity of the survey, it was designed by three family medicine physician experts. Afterwards, two public health experts on questionnaire construction methods evaluated it. Regarding language validation, it was performed by translating it from English to Arabic by an official translator and traslated back to English by a different translator. Afterwards, a pilot study was performed to assess the reliability of the survey and was validated using the Cronbach alpha of 0.7 as set point to measure the internal consistency for each question and subdomain. The survey had an explanatory page before the beginning of the survey which explained different terminology such as family physician, general practitioner, internist and surgeons. The questionnaire included items to assess if there is a difference between family physician and general physician, the number of times the participant visited the family physician the present year, participants opinions about the shortage present in the Primary Health Centers (PHCs) if they prefer to visit the emergency department or the $\mathrm{PHC}$, and the actual role of the PHC and the family physician according to the participants' point of view.

A score was given to the knowledge and awareness or experience and attitude of the participants towards family medicine. Knowledge questions were given a score of [1] for the positive answer and (0) for the negative ones. Every correct answer for diseases treated by the family physician was given a [1] score. Every question was given a score of [1] for the positive answer and (0) for the negative ones. And for the two items: "the role of the family physician is not clearly understood, I don't see any need for primary health care centers". Strongly disagree response was given a score of [4], and for strongly agree it was given (0) score. For the question: "opinion about PHCCs", every negative opinion was given a negative score of $(-1)$. The highest possible score for knowledge and awareness was 20 and for experience and attitude was 16 . A pilot study was conducted to assess the validity and reliability of the developed questionnaire in $10 \%$ of the sample size $(n=650)$. Cronbach alpha coefficient to find the reliability for each instrument was utilized. The Alpha coefficient was high for the instruments with a value of 0.83 . Following the validation of the questionnaire, we asked all included participants to fill the online questionnaire. The pilot study participants were included in the final study sample when the survey was deemed reliable.

\section{Statistical analysis}

All data were analyzed using R software version 4.0.2 and two-sided $P$-value $<0.05$ was considered as statistically significant for all tests. Qualitative data were expressed as numbers and percentages, and the Chi-Square test $\left(x^{2}\right)$ was applied to test the relationship between variables. Quantitiativedata were expressed as mean and standard deviation (Mean $\pm \mathrm{SD}$ ), where Mann-Whitney and Kruskal Wallis Tests were applied for non-parametric variables.In addition, a correlation analysis using the Spearman's test was done to discover the direction and strength of relationship among the variables..

\section{Ethical considerations}

Data were collected anonymously and no identifying information was attached for this online survey. 
Therefore, it will not be possible to withdraw from participation, once the completed questionnaire is submitted online. However, the study participants had the freedom to withdraw anytime during the filling up of the questionnaire online. Approval for the study was obtained from the Research Ethics Committee of King Abdulaziz University with IRB approval number [18-20].

\section{Results}

\section{Sociodemographic characteristics}

A total of 6974 valid participants were included in the current study, where the age group ranged from 25 to 35 years was the most common (37.1\%) followed by 15 to 24 years $(34.6 \%)$ and 36 to 50 years $(21.9 \%)$ groups. The gender distribution was balanced with $51.7 \%$ females versus $48.3 \%$ males while most of the contributors (62.8\%) had the highest education as a bachelor degree. About half of the participants were either single (49.6\%) and the other half were married (46.5\%) and nearly half of them (55.1\%) did not have any children. The monthly income was $<5000$ Saudi Riyal in $38.0 \%$ of the participants, $9.0 \%$ of them were doctors, and $35.5 \%$ were health care providers. Saudi nationality was the majority of the patients (95.3\%) and $34.7 \%$ of them were residing at the central region of Saudi Arabia (Table 1).

\section{Prevalence of chronic illness}

Out of the included participants, $81.3 \%(n=5671)$ did not report any chronic illnesses, while the others $18.7 \%$ ( $n=1303)$ did. Gender, housing, and nationality were all comparable among participants with or without chronic illnesses; however, there were statistically significant differences among those two groups in all other characteristics (Table 1).

Regarding the distribution of different chronic illnesses, $7.6 \%$ had asthma, $6.3 \%$ had hypertension, $6.1 \%$ had diabetes, $3.2 \%$ had psychiatric illness, and $2.8 \%$ had other conditions. There was a statically significant differnces $(P$-value $<0.001)$ among males and females in the rates of hypertension (males: 7.7\%; females: $4.9 \%$ ), diabetes (males: $7.2 \%$; females: $5.0 \%$ ), and psychiatric illness (males: 2.3\%; females: 4.1\%) (Fig. 1).

\section{Perception of family medicine}

The mean awareness and knowledge score for all participants was $9.57 \pm 3.39$ (out of 20 possible points), with a wide range of 1 to 19 and was categorized according to their response to poor knowledge $(<50 \%)$, good knowledge $(50-75 \%)$ and excellent knowledge ( $>75 \%)$. Out of the included participants, $67.8 \%$ of them acknowledged the difference between family physician and general physicians, only $11.4 \%$ did not know about PHCs, and $42.7 \%$ did not know about the numbers of family physicians per Saudi families. In the same context, only $31.6 \%$ were able to identify all listed conditions that family physicians can manage, $52.2 \%$ reported that the family physician can manage emergent cases and $93.3 \%$ agreed that the physician can also manage simple non-emergent conditions. Interestingly, $56.6 \%$ of the participants strongly agreed/ agreed that the role of the family physician is not clearly understood (Table 2).

The mean experience and attitude score for all participants was $10.15 \pm 2.58$ (out of 16 possible points), with a wide range of 1 to 16 . There was no visits of $69.0 \%$ of the participants to any family physician during the last year, $10.6 \%$ of them reported that they do not trust family physicians, only $52.7 \%$ of them identified no problems with their PHCs, and 53.9\% showed a preference to visit emergency department over a PHC. Similarly, $11.3 \%$ of the participants strongly agreed/agreed that there is no need for PHCs and $30.6 \%$ of them just visited PHC to get referrals. However, 69.4\% acknowledged how easy and approachable PHC can be (Table 3).

Correlation analyses were performed to test the association of different predictors to patients' scores. Patients' perceptions, whether awareness and knowledge or experience and attitude scores, were significantly correlated $(P$-value $<0.001)$ to chronic illness status, being a healthcare worker, job, marital status, and gender factors. Moreover, experience and attitude score was additionally correlated to residence region (Spearman's rho $=0.03$; $P$-value $=0.034)$ and participants' nationality (Spearman's rho $=0.07 ; P$-value $<0.001)($ Table 4$)$.

\section{Discussion}

In this study, we investigated the satisfaction and awareness among the public about family physicians and the factors related to enhancing satisfaction.. This indicates the huge efforts that are being exerted to increase access to universal health care across the country.

We have obtained 6974 results from patients who responded to our questionnaire. According to the demographics analysis, age, educational level, marital status, number of children, income, job, being a healthcare provider, and region were significant variables among the study participants. Family medicine as a specialty involves taking care of many morbidities ranging between simple illnesses to chronic ones as hypertension, diabetes, and asthma regardless of the gender and age of the patients [25]. Although $67.8 \%$ of the study participants differentiated between general physicians and family physicians, we found that $56.6 \%$ of the included participants did not clearly understand the role of the family 
Table 1 Sociodemographic characteristics of the included participants

\begin{tabular}{|c|c|c|c|c|c|c|c|c|}
\hline \multirow[t]{3}{*}{ Variables } & & \multicolumn{6}{|c|}{ Chronic Illness } & \multirow[t]{3}{*}{$P$-value } \\
\hline & & \multicolumn{2}{|l|}{ Yes } & \multicolumn{2}{|l|}{ No } & \multicolumn{2}{|l|}{ Total } & \\
\hline & & $n$ & $\%$ & $\mathrm{n}$ & $\%$ & $\mathrm{~N}$ & $\%$ & \\
\hline \multirow[t]{4}{*}{ Age } & $15-24$ & 341 & 26.2 & 2069 & 36.5 & 2410 & 34.6 & $<0.001^{b}$ \\
\hline & $25-35$ & 354 & 27.2 & 2234 & 39.4 & 2588 & 37.1 & \\
\hline & $36-50$ & 370 & 28.4 & 1154 & 20.3 & 1524 & 21.9 & \\
\hline & $>50$ & 238 & 18.3 & 214 & 3.8 & 452 & 6.5 & \\
\hline \multirow[t]{2}{*}{ Gender } & Male & 655 & 50.3 & 2710 & 47.8 & 3365 & 48.3 & 0.106 \\
\hline & Female & 648 & 49.7 & 2961 & 52.2 & 3609 & 51.7 & \\
\hline \multirow[t]{6}{*}{ Educational level } & No School & 149 & 11.5 & 418 & 7.4 & 567 & 8.2 & $<0.001^{b}$ \\
\hline & Diploma & 204 & 15.7 & 760 & 13.4 & 964 & 13.9 & \\
\hline & Student & 107 & 8.2 & 437 & 7.7 & 544 & 7.8 & \\
\hline & Bachelor & 676 & 52.1 & 3695 & 65.3 & 4371 & 62.8 & \\
\hline & Master & 109 & 8.4 & 256 & 4.5 & 365 & 5.2 & \\
\hline & Doctorate & 53 & 4.1 & 93 & 1.6 & 146 & 2.1 & \\
\hline \multirow[t]{4}{*}{ Marital status } & Single & 489 & 37.5 & 2973 & 52.4 & 3462 & 49.6 & $<0.001^{b}$ \\
\hline & Married & 727 & 55.8 & 2515 & 44.3 & 3242 & 46.5 & \\
\hline & Widowed & 36 & 2.8 & 51 & 0.9 & 87 & 1.2 & \\
\hline & Divorced & 51 & 3.9 & 132 & 2.3 & 183 & 2.6 & \\
\hline \multirow[t]{4}{*}{ Number of children } & No children & 534 & 41.0 & 3312 & 58.4 & 3846 & 55.1 & $<0.001^{b}$ \\
\hline & One & 111 & 8.5 & 463 & 8.2 & 574 & 8.2 & \\
\hline & $2-3$ & 190 & 14.6 & 901 & 15.9 & 1091 & 15.6 & \\
\hline & $>3$ & 468 & 35.9 & 995 & 17.5 & 1463 & 21.0 & \\
\hline \multirow[t]{2}{*}{ Home } & My own & 881 & 67.6 & 3692 & 65.1 & 4573 & 65.6 & 0.086 \\
\hline & Rental & 422 & 32.4 & 1979 & 34.9 & 2401 & 34.4 & \\
\hline \multirow[t]{5}{*}{ Income/ month } & $<5000$ SR & 396 & 30.4 & 2254 & 39.7 & 2650 & 38.0 & $<0.001^{b}$ \\
\hline & $5000-10,000$ SR & 315 & 24.2 & 1343 & 23.7 & 1658 & 23.8 & \\
\hline & $10,000-15,000$ SR & 293 & 22.5 & 1139 & 20.1 & 1432 & 20.5 & \\
\hline & $15,000-20,000$ SR & 173 & 13.3 & 550 & 9.7 & 723 & 10.4 & \\
\hline & $>20,000 \mathrm{SR}$ & 126 & 9.7 & 385 & 6.8 & 511 & 7.3 & \\
\hline \multirow[t]{6}{*}{ Job } & Doctor & 98 & 7.5 & 528 & 9.3 & 626 & 9.0 & $<0.001^{b}$ \\
\hline & Engineer & 71 & 5.4 & 204 & 3.6 & 275 & 3.9 & \\
\hline & Teacher & 231 & 17.7 & 689 & 12.1 & 920 & 13.2 & \\
\hline & Student & 306 & 23.5 & 1840 & 32.4 & 2146 & 30.8 & \\
\hline & Nurse & 48 & 3.7 & 233 & 4.1 & 281 & 4.0 & \\
\hline & Other & 549 & 42.1 & 2177 & 38.4 & 2726 & 39.1 & \\
\hline \multirow[t]{2}{*}{ Are you a health care provider? } & No & 945 & 72.5 & 3554 & 62.7 & 4499 & 64.5 & $<0.001^{b}$ \\
\hline & Yes & 358 & 27.5 & 2117 & 37.3 & 2475 & 35.5 & \\
\hline \multirow[t]{2}{*}{ Nationality } & Saudi & 1253 & 96.2 & 5386 & 95.0 & 6639 & 95.3 & 0.064 \\
\hline & Non-Saudi & 49 & 3.8 & 282 & 5.0 & 331 & 4.7 & \\
\hline \multirow[t]{5}{*}{ Region } & Northern & 134 & 10.3 & 692 & 12.2 & 826 & 11.8 & $0.003^{\mathrm{a}}$ \\
\hline & Southern & 230 & 17.7 & 1194 & 21.1 & 1424 & 20.4 & \\
\hline & Eastern & 161 & 12.4 & 721 & 12.7 & 882 & 12.6 & \\
\hline & Western & 278 & 21.3 & 1143 & 20.2 & 1421 & 20.4 & \\
\hline & Central & 500 & 38.4 & 1921 & 33.9 & 2421 & 34.7 & \\
\hline
\end{tabular}

\footnotetext{
${ }^{a}$ Statistically significant $<0.05 ;{ }^{\mathrm{b}}$ Statistically significant $<0.001$
} 


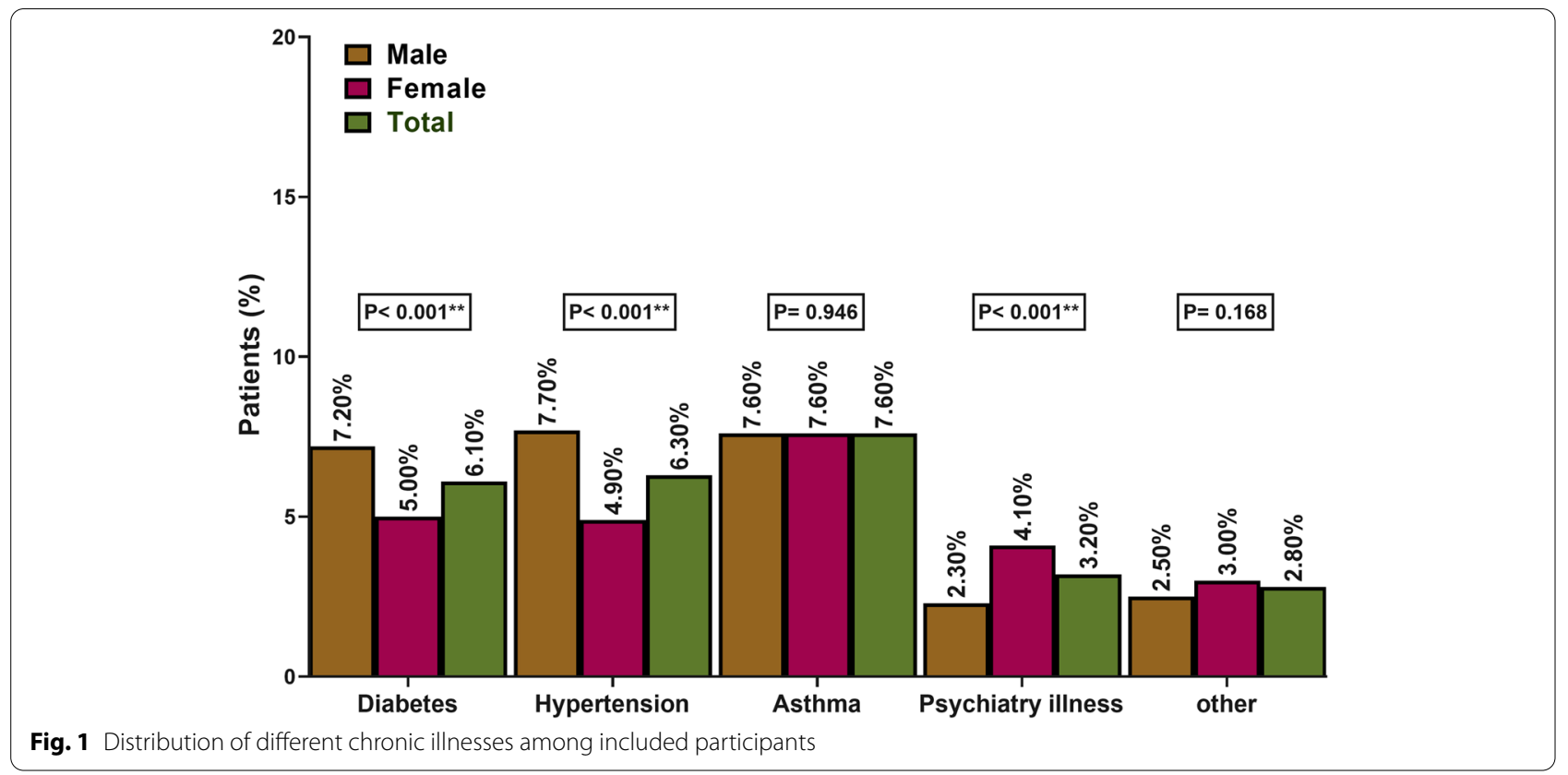

physicians. Elagi et al. [26] reported a lower rate of $43.7 \%$ among their included participants from Jazan, Saudi Arabia. These results are similar to the previous worldwide reports in Denmark [27], Nairobi [28], and Ireland [29]. Therefore, it has been concluded that patients prefer to seek initial care from specialized personnel of other medical specialties than family medicine physicians [28].

The importance of family medicine was measured by the ability of family physicians to deal with patients and manage their illnesses. In this study, we found a huge variability in what people think family physicians can treat. Almost all participants (93.3\%) agreed that family physicians can treat non-emergent cases as simple wounds that do not need suturing or surgical intervention while opinions about whether family physicians can manage emergent caseswas almost the same. However, our analysis showed that most participants trust their family physicians which reflects that a large number of the population believes in their importance. Moreover, around $69.9 \%$ of the study population did not agree to this statement "I Don't see any need for primary health care centers" which indicates the importance of PHCC among the public. Elagi et al. [26] estimated that $67.3 \%$ of their study population trusted in their family physicians as the primary healthcare providers. However, the authors reported a rate of $28.3 \%$ for patients' satisfaction. Moreover, Mohamoud et al. [28] reported that only a small proportion of the included participants had confidence in their family physicians' ability to treat diabetes, tuberculosis, human immunodeficiency virus, anxiety, and depression. On the other hand, previous studies have estimated the rate of satisfaction among the public regarding the roles of family physicians to be ranging between 60 and 90\% [21,30-32]. This indicates that the quality of the offered care by family physicians is hugely variable among the different populations depending on many factors which can hugely affect patient satisfaction.

To identify these factors, we studied the correlation between certain variables and the awareness and knowledge, in addition to the experience and attitudes scores. According to our analysis, having chronic illnesses, being a healthcare worker, job, marital status, and gender significantly affected the awareness and knowledge scores of the included participants. Moreover, the same variables in addition to the region and nationality were also significantly associated with the experience and attitudes of the patients towards family medicine. The significance of different regions and nationalities may reflect that different cultures and circumstances can easily affect patients' awareness and attitudes. Besides, previous studies have reported that old age and chronic illnesses were significantly associated with seeking and giving the advantage to family physicians [26, 33, 34]. Bawakid et al. [21] also reported that gender was a significant factor affecting patients' satisfaction. Additionally, the authors have also identified that consulting the same physician was also correlated with patients' satisfaction. The awareness and attitudes of the public can be improved by enhancing the communication between the family physicians and the public. This can be achieved by providing educational 
Table 2 Awareness and knowledge towards family medicine among the included participants

\begin{tabular}{|c|c|c|c|c|c|c|c|c|}
\hline \multirow[t]{3}{*}{ Variables } & & \multicolumn{6}{|c|}{ Chronic Illness } & \multirow[t]{3}{*}{$P$-value } \\
\hline & & \multicolumn{2}{|l|}{ Yes } & \multicolumn{2}{|l|}{ No } & \multicolumn{2}{|l|}{ Total } & \\
\hline & & $\mathrm{n}$ & $\%$ & $\mathbf{n}$ & $\%$ & $\mathbf{N}$ & $\%$ & \\
\hline \multirow[t]{3}{*}{ Is there difference between family physician and general physician } & No & 219 & 16.8 & 824 & 14.5 & 1043 & 15.0 & \multirow[t]{3}{*}{$0.035^{\mathrm{a}}$} \\
\hline & Yes & 846 & 64.9 & 3885 & 68.5 & 4731 & 67.8 & \\
\hline & I don't know & 238 & 18.3 & 962 & 17.0 & 1200 & 17.2 & \\
\hline \multirow[t]{2}{*}{ I don't know about PHCCs } & No & 1184 & 90.9 & 4996 & 88.1 & 6180 & 88.6 & \multirow[t]{2}{*}{$0.005^{\circ}$} \\
\hline & Yes & 119 & 9.1 & 675 & 11.9 & 794 & 11.4 & \\
\hline \multirow[t]{3}{*}{ Family physician can only treat flu and refer you to other specialty } & No & 398 & 30.5 & 1805 & 31.8 & 2203 & 31.6 & \multirow[t]{3}{*}{$0.013^{\circ}$} \\
\hline & Yes & 497 & 38.1 & 1924 & 33.9 & 2421 & 34.7 & \\
\hline & I don't know & 408 & 31.3 & 1942 & 34.2 & 2350 & 33.7 & \\
\hline \multirow[t]{3}{*}{ Number of family physician per Saudi families are } & Enough & 0 & 0.0 & 0 & 0.0 & 0 & 0.0 & \multirow[t]{3}{*}{$0.004^{2}$} \\
\hline & Not enough & 793 & 60.9 & 3206 & 56.5 & 3999 & 57.3 & \\
\hline & I don't know & 510 & 39.1 & 2465 & 43.5 & 2975 & 42.7 & \\
\hline \multicolumn{9}{|l|}{ Family physician can treat the following } \\
\hline \multirow[t]{2}{*}{ Chronic diseases (diabetes, hypertension, osteoarthritis, etc.) } & No & 623 & 47.8 & 3192 & 56.3 & 3815 & 54.7 & \multirow[t]{2}{*}{$<0.001^{b}$} \\
\hline & Yes & 680 & 52.2 & 2479 & 43.7 & 3159 & 45.3 & \\
\hline \multirow[t]{2}{*}{ Acute disease (flu, gastroenteritis, urinary tract infection, etc.) } & No & 878 & 67.4 & 3800 & 67.0 & 4678 & 67.1 & \multirow[t]{2}{*}{0.795} \\
\hline & Yes & 425 & 32.6 & 1871 & 33.0 & 2296 & 32.9 & \\
\hline \multirow[t]{2}{*}{ Gynecological diseases } & No & 1192 & 91.5 & 5107 & 90.1 & 6299 & 90.3 & \multirow[t]{2}{*}{0.116} \\
\hline & Yes & 111 & 8.5 & 564 & 9.9 & 675 & 9.7 & \\
\hline \multirow[t]{2}{*}{ Pediatric diseases } & No & 984 & 75.5 & 4209 & 74.2 & 5193 & 74.5 & 0.332 \\
\hline & Yes & 319 & 24.5 & 1462 & 25.8 & 1781 & 25.5 & \\
\hline Dermatological diseases & No & 1141 & 87.6 & 4978 & 87.8 & 6119 & 87.7 & 0.833 \\
\hline & Yes & 162 & 12.4 & 693 & 12.2 & 855 & 12.3 & \\
\hline Psychiatric illness & No & 1182 & 90.7 & 5080 & 89.6 & 6262 & 89.8 & 0.222 \\
\hline & Yes & 121 & 9.3 & 591 & 10.4 & 712 & 10.2 & \\
\hline Preventive vaccination & No & 848 & 65.1 & 3573 & 63.0 & 4421 & 63.4 & 0.161 \\
\hline & Yes & 455 & 34.9 & 2098 & 37.0 & 2553 & 36.6 & \\
\hline All the above & No & 957 & 73.4 & 3810 & 67.2 & 4767 & 68.4 & $<0.001^{b}$ \\
\hline & Yes & 346 & 26.6 & 1861 & 32.8 & 2207 & 31.6 & \\
\hline None of the above & No & 1203 & 92.3 & 5220 & 92.0 & 6423 & 92.1 & 0.737 \\
\hline & Yes & 100 & 7.7 & 451 & 8.0 & 551 & 7.9 & \\
\hline Can family physician manage emergency cases such as cardiac arrest? & No & 477 & 49.4 & 1966 & 47.5 & 2443 & 47.8 & 0.271 \\
\hline & Yes & 488 & 50.6 & 2176 & 52.5 & 2664 & 52.2 & \\
\hline Can family physician manage non-emergency cases such as simple & No & 100 & 8.5 & 323 & 6.3 & 423 & 6.7 & $0.007^{\mathrm{a}}$ \\
\hline wounds that don't require suturing & Yes & 1072 & 91.5 & 4784 & 93.7 & 5856 & 93.3 & \\
\hline Do your PHCCs have an urgent care clinic? & No & 520 & 57.9 & 1915 & 50.9 & 2435 & 52.2 & $<0.001^{b}$ \\
\hline & Yes & 378 & 42.1 & 1850 & 49.1 & 2228 & 47.8 & \\
\hline & I don't know & 0 & 0.0 & 0 & 0.0 & 0 & 0.0 & \\
\hline The role of family physician is not clearly understood & Strongly Agree & 374 & 28.7 & 1387 & 24.5 & 1761 & 25.3 & $0.012^{\mathrm{a}}$ \\
\hline & Agree & 372 & 28.5 & 1812 & 32.0 & 2184 & 31.3 & \\
\hline & Neutral & 334 & 25.6 & 1542 & 27.2 & 1876 & 26.9 & \\
\hline & Disagree & 164 & 12.6 & 687 & 12.1 & 851 & 12.2 & \\
\hline & Strongly Disagree & 59 & 4.5 & 243 & 4.3 & 302 & 4.3 & \\
\hline
\end{tabular}

\footnotetext{
${ }^{a}$ Statistically significant $<0.05$; ${ }^{b}$ Statistically significant $<0.001$; $P H C C$ primary health care center
} 
Table 3 Experience and attitudes towards family medicine among the included participants

\begin{tabular}{|c|c|c|c|c|c|c|c|c|}
\hline \multirow[t]{3}{*}{ Variables } & & \multicolumn{6}{|c|}{ Chronic Illness } & \multirow[t]{3}{*}{$P$-value } \\
\hline & & \multicolumn{2}{|l|}{ Yes } & \multicolumn{2}{|l|}{ No } & \multicolumn{2}{|l|}{ Total } & \\
\hline & & $\mathbf{n}$ & $\%$ & $\mathbf{n}$ & $\%$ & $\mathbf{N}$ & $\%$ & \\
\hline \multirow[t]{3}{*}{ Number of times you visited your family physician this year } & 0 & 723 & 55.5 & 4089 & 72.1 & 4812 & 69.0 & \multirow[t]{3}{*}{$<0.001^{b}$} \\
\hline & $1-3$ & 402 & 30.9 & 1270 & 22.4 & 1672 & 24.0 & \\
\hline & $>4$ & 178 & 13.7 & 312 & 5.5 & 490 & 7.0 & \\
\hline \multirow[t]{2}{*}{ Do you trust family physicians } & Yes & 934 & 88.2 & 4068 & 89.7 & 5002 & 89.4 & \multirow[t]{2}{*}{0.146} \\
\hline & No & 125 & 11.8 & 466 & 10.3 & 591 & 10.6 & \\
\hline \multicolumn{9}{|l|}{ Opinion about the PHCCs } \\
\hline \multirow[t]{2}{*}{ Staff are lacking knowledge } & No & 1035 & 79.4 & 4558 & 80.4 & 5593 & 80.2 & \multirow[t]{2}{*}{0.442} \\
\hline & Yes & 268 & 20.6 & 1113 & 19.6 & 1381 & 19.8 & \\
\hline \multirow[t]{2}{*}{ Lacking staff } & No & 962 & 73.8 & 4268 & 75.3 & 5230 & 75.0 & \multirow[t]{2}{*}{0.282} \\
\hline & Yes & 341 & 26.2 & 1403 & 24.7 & 1744 & 25.0 & \\
\hline \multirow[t]{2}{*}{ Difficult to open file } & No & 1152 & 88.4 & 5178 & 91.3 & 6330 & 90.8 & \multirow[t]{2}{*}{$0.001^{a}$} \\
\hline & Yes & 151 & 11.6 & 493 & 8.7 & 644 & 9.2 & \\
\hline \multirow[t]{2}{*}{ Long waiting hours } & No & 1023 & 78.5 & 4439 & 78.3 & 5462 & 78.3 & \multirow[t]{2}{*}{0.852} \\
\hline & Yes & 280 & 21.5 & 1232 & 21.7 & 1512 & 21.7 & \\
\hline \multirow[t]{2}{*}{ No proper facility (labs/radiology. Etc.) } & No & 930 & 71.4 & 4039 & 71.2 & 4969 & 71.3 & \multirow[t]{2}{*}{0.913} \\
\hline & Yes & 373 & 28.6 & 1632 & 28.8 & 2005 & 28.7 & \\
\hline \multirow[t]{2}{*}{ Nothing wrong with our PHCCS } & No & 628 & 48.2 & 2673 & 47.1 & 3301 & 47.3 & \multirow[t]{2}{*}{0.489} \\
\hline & Yes & 675 & 51.8 & 2998 & 52.9 & 3673 & 52.7 & \\
\hline \multirow[t]{2}{*}{ Do you prefer visiting emergency department or PHCC? } & Emergency department & 693 & 53.2 & 3066 & 54.1 & 3759 & 53.9 & \multirow[t]{2}{*}{0.566} \\
\hline & Primary health care center & 610 & 46.8 & 2605 & 45.9 & 3215 & 46.1 & \\
\hline \multirow[t]{5}{*}{ Don't see any need for PHCCs } & Strongly Agree & 82 & 6.3 & 266 & 4.7 & 348 & 5.0 & \multirow[t]{5}{*}{$0.008^{\mathrm{a}}$} \\
\hline & Agree & 95 & 7.3 & 343 & 6.0 & 438 & 6.3 & \\
\hline & Neutral & 266 & 20.4 & 1049 & 18.5 & 1315 & 18.9 & \\
\hline & Disagree & 386 & 29.6 & 1767 & 31.2 & 2153 & 30.9 & \\
\hline & Strongly Disagree & 474 & 36.4 & 2246 & 39.6 & 2720 & 39.0 & \\
\hline \multirow[t]{3}{*}{ Do you visit PHCC just to get referrals? } & No & 670 & 51.4 & 2859 & 50.4 & 3529 & 50.6 & $0.012^{\mathrm{a}}$ \\
\hline & Yes & 424 & 32.5 & 1708 & 30.1 & 2132 & 30.6 & \\
\hline & I don't visit primary health care center & 209 & 16.0 & 1104 & 19.5 & 1313 & 18.8 & \\
\hline Do you approach easily to PHCC and have easy access to & No & 220 & 16.9 & 790 & 13.9 & 1010 & 14.5 & $0.021^{\mathrm{a}}$ \\
\hline your neighbor center? & Yes & 885 & 67.9 & 3957 & 69.8 & 4842 & 69.4 & \\
\hline & I don't visit primary health care center & 198 & 15.2 & 924 & 16.3 & 1122 & 16.1 & \\
\hline
\end{tabular}

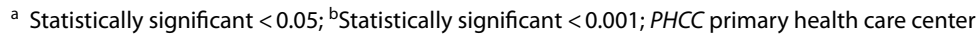

programs to furtherly elucidate the roles of family physicians in addition to further training of family physicians to properly manage the different forms of chronic illnesses and emergencies. Al-Doghaither et al. [31 reported that better communication skills and deep relationships between the patients and physicians were generally associated with better satisfaction and attitudes.

Limitations to our study include the nature of data collection which was online-based with a non-parametric sampling techinque utilized to recruit more respondents, and therefore, sampling bias may have occurred. In addition, some of the survey questions were negatively phrased which makes it susceptible to response bias.
Furthermore, using an online-based survey did not allow us to know the response rate of the population nor the denominator. This may have also affected the results in some correlations due to the nature of this sampling. In addition, some variables was not explored sufficiently such as gender and jobs to find which kind were more satisfied.

\section{Conclusion}

The results of this study indicate that the mean awareness and experience scores are generally moderate although most patients trusted family physicians. Having chronic illnesses, being a healthcare worker, job, 
Table 4 Correlation between patients' scores and different predictors

\begin{tabular}{|c|c|c|c|c|}
\hline \multirow{2}{*}{$\begin{array}{l}\text { Variables } \\
\text { Chronic illness }\end{array}$} & \multicolumn{2}{|c|}{$\begin{array}{l}\text { Awareness and } \\
\text { Knowledge Score }\end{array}$} & \multicolumn{2}{|c|}{$\begin{array}{l}\text { Experience and } \\
\text { Attitudes Score }\end{array}$} \\
\hline & $\begin{array}{l}\text { Spearman's } \\
\text { rho }\end{array}$ & 0.04 & $\begin{array}{l}\text { Spearman's } \\
\text { rho }\end{array}$ & 0.09 \\
\hline & P-value & $<0.001^{b}$ & P-value & $<0.001^{b}$ \\
\hline \multirow[t]{2}{*}{$\begin{array}{l}\text { Healthcare } \\
\text { worker }\end{array}$} & $\begin{array}{l}\text { Spearman's } \\
\text { rho }\end{array}$ & -0.20 & $\begin{array}{l}\text { Spearman's } \\
\text { rho }\end{array}$ & -0.04 \\
\hline & P-value & $<0.001^{b}$ & P-value & $<0.001^{b}$ \\
\hline \multirow[t]{2}{*}{ Region } & $\begin{array}{l}\text { Spearman's } \\
\text { rho }\end{array}$ & $<0.01$ & $\begin{array}{l}\text { Spearman's } \\
\text { rho }\end{array}$ & 0.03 \\
\hline & P-value & 0.900 & P-value & $0.034^{a}$ \\
\hline \multirow[t]{2}{*}{ Nationality } & $\begin{array}{l}\text { Spearman's } \\
\text { rho }\end{array}$ & -0.02 & $\begin{array}{l}\text { Spearman's } \\
\text { rho }\end{array}$ & 0.07 \\
\hline & P-value & 0.065 & P-value & $<0.001^{b}$ \\
\hline \multirow[t]{2}{*}{ Job } & $\begin{array}{l}\text { Spearman's } \\
\text { rho }\end{array}$ & -0.08 & $\begin{array}{l}\text { Spearman's } \\
\text { rho }\end{array}$ & 0.07 \\
\hline & P-value & $<0.001^{b}$ & P-value & $<0.001^{b}$ \\
\hline \multirow[t]{2}{*}{ Income } & $\begin{array}{l}\text { Spearman's } \\
\text { rho }\end{array}$ & 0.01 & $\begin{array}{l}\text { Spearman's } \\
\text { rho }\end{array}$ & -0.01 \\
\hline & P-value & 0.266 & P-value & 0.242 \\
\hline \multirow[t]{2}{*}{ Marital status } & $\begin{array}{l}\text { Spearman's } \\
\text { rho }\end{array}$ & -0.04 & $\begin{array}{l}\text { Spearman's } \\
\text { rho }\end{array}$ & -0.07 \\
\hline & P-value & $<0.001^{b}$ & P-value & $<0.001^{b}$ \\
\hline \multirow[t]{2}{*}{$\begin{array}{l}\text { Educational } \\
\text { level }\end{array}$} & $\begin{array}{l}\text { Spearman's } \\
\text { rho }\end{array}$ & 0.02 & $\begin{array}{l}\text { Spearman's } \\
\text { rho }\end{array}$ & 0 \\
\hline & P-value & 0.100 & P-value & 0.966 \\
\hline \multirow[t]{2}{*}{ Gender } & $\begin{array}{l}\text { Spearman's } \\
\text { rho }\end{array}$ & -0.06 & $\begin{array}{l}\text { Spearman's } \\
\text { rho }\end{array}$ & -0.04 \\
\hline & P-value & $<0.001^{b}$ & P-value & $<0.001^{b}$ \\
\hline \multirow[t]{2}{*}{ Age group } & $\begin{array}{l}\text { Spearman's } \\
\text { rho }\end{array}$ & -0.01 & $\begin{array}{l}\text { Spearman's } \\
\text { rho }\end{array}$ & -0.01 \\
\hline & P-value & 0.389 & P-value & 0.470 \\
\hline
\end{tabular}

${ }^{a}$ Statistically significant $<0.05 ;{ }^{\text {b }}$ Statistically significant $<0.001$

marital status, and gender significantly affected the awareness and experience scores of the included participants. Therefore, these factors should be considered when trying to increase public awareness and enhance the experience with family physicians by explaining the role of family medicine physicina through campaigns, flyers or public advertisements.

\section{Acknowledgements}

The authors would like to thank Dr. Yahia Mater Alkhaldi, for his continous support in reviewing the questionnaire and helping in validating it, without his assistance this manuscript would not have been possible.

\section{Authors' contributions}

M.M. conceptualized the idea, supervised the data collection, analyzed and wrote the final data. R.M. and M.T. supervized the data collection, filtered, analyzed, and wrote the results. R.A., A.A., J.A., H.B., A.A. and M.S. took part in data collection, data filteration, data interpretation, reference exctractions, writing and proofreading of the final paper. The author(s) read and approved the final manuscript.
Funding

None.

\section{Availability of data and materials}

The datasets generated and/or analysed during the current study are available within the article. However, raw data and the questionnaire due the institute's IRB polict are available from the corresponding author on request.

\section{Declarations}

\section{Ethics approval and consent to participate}

All methods were performed in accordance with the relevant guidelines and regulations Declaration of Helsinki. Approval for the study was obtained from the Research Ethics Committee of King Abdulaziz University with IRB approval number [18-20]. Informed Consent was obtained from participants and from either the parent or legal guardian of participants who are below the age of 16years

\section{Consent for publication}

Not Applicable.

\section{Competing interests}

None to decalare.

\section{Author details}

${ }^{1}$ Department of Family Medicine, Faculty of Medicine, King Abdulaziz University, P.O.Box 80205, Jeddah 21589, Saudi Arabia. ${ }^{2}$ Department of Emergency Medicine, AlNoor Specialist Hospital, Mecca, Saudi Arabia. ${ }^{3}$ Department Of Family Medicine, King Fahad Armed Forces Hospital, Jeddah, Saudi Arabia.

${ }^{4}$ Faculty of Medicine, King Abdulaziz University, Jeddah, Saudi Arabia. ${ }^{5}$ College of Medicine, Taif University, Taif, Saudi Arabia. ${ }^{6}$ Alkhaldia Primary Health Care, Ministry of Health, Alhassa, Saudi Arabia. ${ }^{7}$ Alrabea Primary Health Care, Ministry of Health, Riyadh, Saudi Arabia. ${ }^{8}$ Alnadwa Primary Health Care, Ministry of Health, Riyadh, Saudi Arabia.

Received: 18 April 2021 Accepted: 3 December 2021

Published online: 21 January 2022

\section{References}

1. Rakel RE. Essential family medicine: Fundamentals and case studies, third edition2006. 1-740 p.

2. Xierali IM, Nivet MA. The racial and ethnic composition and distribution of primary care physicians. J Health Care Poor Underserved. 2018;29(1):556.

3. Al Asmri M, Almalki MJ, Fitzgerald G, Clark M. The public health care system and primary care services in Saudi Arabia: a system in transition. Eastern Mediterranean Health. 2020;26(4):468-76.

4. Wong ELY, Coulter A, Hewitson P, Cheung AWL, Yam CHK, Lui SF, et al. Patient experience and satisfaction with inpatient service: development of short form survey instrument measuring the core aspect of inpatient experience. PLoS One. 2015;10(4):e0122299-e.

5. Tsai TC, Orav EJ, Jha AK. Patient satisfaction and quality of surgical care in US hospitals. Ann Surg. 2015;261(1):2-8.

6. Hall J, Roter D, Blanch-Hartigan D, Mast M, Pitegoff C. How patient-centered do female physicians need to be? Analogue Patients'satisfaction with male and female Physicians' identical behaviors. Health Commun. 2015;30:894-900

7. Al-Khaldi YM, Al-Ghamdi EA, Al-Mogbil TI, Al-Khashan HI. Family medicine practice in Saudi Arabia: the current situation and proposed strategic directions plan 2020. J Family Community Med. 2017;24(3):156-63.

8. Robbins JA, Bertakis K, Helms LJ, Azari R, Callahan E, Creten DA. The influence of physician practice behaviors on patient satisfaction. Fam Med. 1993:25:17-20

9. Street RL. Information-giving in medical consultations: the influence of patients' communicative styles and personal characteristics. Soc Sci Med. 1991;32(5):541-8.

10. Hale A, Coombes I, Stokes J, Aitken S, Clark F, Nissen L. Patient satisfaction from two studies of collaborative doctor-pharmacist prescribing in Australia. Health Expect. 2016;19(1):49-61. 
11. Kincey J, Bradshaw P, Ley P. Patients'satisfaction and reported acceptance of advice in general practice. J R Coll Gen Pract. 1975;25(157):558-66.

12. Osman $\mathrm{H}$, Romani $\mathrm{M}$, Hlais $\mathrm{S}$. Family medicine in Arab countries. Fam Med. 2011;43:37-42.

13. Al Bar AA. Twenty years of family medicine education in Saudi Arabia; 1999.

14. Health Mo. Health Statistical Year Book 2012.

15. Medicine SSoFaC. 2021 [Available from: http://www.ssfcm.org/public/ english/Index/index/secld/0/.

16. Al-Khaldi Y, Al-Megbil T, Al-Shmmari S, Al-Yahya O, AlBar A, Aldawood K, et al. Challenges facing postgraduate training in family medicine in Saudi Arabia: patterns and solutions. J Health Specialties. 2014;2:61.

17. Alshareef M. Satisfaction of family physicians during their training program, Jeddah, Saudi Arabia,Int J Med Sci Public Health 2014;3:4.

18. Abdulrahman K, Al Dakheel A, Khalid D, Abdulrahman A. Family medicine residency program in Kingdom of Saudi Arabia: residents opinion. J Med Sci Pak J Med Sci July-September. 2006;22:250-7.

19. Al-Khaldi Y, AlDawood K, AlKhudeer B, AlSaqqaf A. Satisfaction of trainees of Saudi diploma family medicine, Saudi Arabia,Educ Primary Care 2016:27:1-3.

20. Baker R, Mainous lii AG, Gray DP, Love MM. Exploration of the relationship between continuity, trust in regular doctors and patient satisfaction with consultations with family doctors. Scand J Prim Health Care. 2003;21(1):27-32.

21. Bawakid K, Rashid OA, Mandoura N, Usman Shah HB, Ahmed WA, Ibrahim A. Patients'satisfaction regarding family physician's consultation in primary healthcare centers of Ministry of Health, Jeddah,J Family Med Prim Care 2017;6(4):819-823.

22. Raina SK. Establishing association. Indian J Med Res. 2015;141(1):127-

23. Grootens-Wiegers $P$, Hein IM, van den Broek JM, de Vries MC. Medical decision-making in children and adolescents: developmental and neuroscientific aspects. BMC Pediatr. 2017;17(1):120.

24. Steinberg L. Does recent research on adolescent brain development inform the mature minor doctrine? J Med Philosophy. 2013;38(3):256-67.

25. Al-Khaldi Y, Al-Ghamdi E, Al-Megbil T, Al-Khashan H. Family medicine practice in Saudi Arabia: the current situation and proposed strategic directions plan 2020. J Fam Community Med. 2017;24:156.

26. Elagi AAA, Jaber BA, Wassly AHA, Ahmed RMS, Bosily FAA. Public's perception and satisfaction on the role and services provided by family physicians in Saudi Arabia: a cross-sectional study. J Family Med Prim Care. 2019;8(10):3282-6.

27. Aw Murphy obotDGPVTSTYG. Opening Pandora's box: patients'attitudes towards trainees. Fam Pract 1995;12(3):318-323.

28. Mohamoud G, Mash B, Merali M, Orwa J, Mahoney M. Perceptions regarding the scope of practice of family doctors amongst patients in primary care settings in Nairobi. Afr J Prim Health Care Fam Med. 2018;10(1):e1-7.

29. Fuglsang H, Olesgaard P, Pedersen N, Olesen F. Patients' attitudes towards and satisfaction with interns in general practice. Practicing interns and patient satisfaction. Ugeskr Laeger. 1996;158(41):5768-72.

30. Al-Doghaither A, Saeed A. Consumers' satisfaction with primary health services in the city of Jeddah, Saudi Arabia. Saudi Med J. 2000;21:447-54.

31. Al-Doghaither AH, Abdelrhman BM, Saeed AA, Al-Kamil AA, Majzoub MM. Patients'satisfaction with primary health care centers services in Kuwait City, Kuwait. J Family Community Med. 2001;8(3):59-65.

32. Ahmed Abd al K, Aday LA, Walker GM. Patient satisfaction in government health facilities in the State of Qatar. J Community Health 1996;21(5):349-358.

33. Malcolm CE, Wong KK, Elwood-Martin R. Patients' perceptions and experiences of family medicine residents in the office. Can Fam Physician. 2008;54(4):570-1.e5716.

34. Jones R. Patients' attitudes to chaperones. J R Coll Gen Pract. 1985:35(273):192-3

\section{Publisher's Note}

Springer Nature remains neutral with regard to jurisdictional claims in published maps and institutional affiliations.

Ready to submit your research? Choose BMC and benefit from:

- fast, convenient online submission

- thorough peer review by experienced researchers in your field

- rapid publication on acceptance

- support for research data, including large and complex data types

- gold Open Access which fosters wider collaboration and increased citations

- maximum visibility for your research: over $100 \mathrm{M}$ website views per year

At BMC, research is always in progress.

Learn more biomedcentral.com/submissions 